\title{
Presentation of JCSW Issue 2011/1
}

Paul Stephens, Professor, University of Stavanger, Norway Email: paul.stephens@uis.no 
In the April 2011 issue of JCSW, there are four articles. In each one, the comparative feature is to be found in the study of different nations.

In her student essay on community work in a rural village in Nepal, Shovita Adhikari reflects on her position as a social worker who also adopts an advocacy researcher role. She sets herself the task of helping to integrate people from the lower Dalit caste into their local community. This is difficult because the higher caste, whose members occasionally inhabit some of the same social spaces as the lower caste, insist on rigid demarcation.

The fact that the researcher herself is from the higher Brahmin caste created numerous communication problems with the Dalits, but to her credit, she persevered. Using critical incidents and critical reflections based on anti-oppressive theory, Adhikari exposes a whole variety of sometimes open, sometimes nuanced conceptions of upper and lower castes towards each other. Particularly revealing is the author's disclosure of the awkwardness that members of both castes often feel if another caste member "breaks the rules".

Adhikari also finds that gender factors permeate caste culture, noting how Dalit women suffer more discrimination than their male counterparts. Put simply, these women suffer the burden of both gender and caste discrimination.

What impresses me most about this article is the author's courage and dedication. She exposes herself to the hostility of her own elite Brahmin caste and the low-status Dalit caste in order to get the job done. This is truly in the spirit of advocacy research.

The author of the second article, Anne Juberg, explores how 17 "somewhat deviant" adolescents in Norway position themselves in society. While they experiment with intoxicants and engage in minor delinquency, these young people see their current identities as tentative, rather than finished business. They understand that adults are worried on their behalf, but do not always share this concern. Indeed, their future perspectives are broadly in line with conventional Norwegian norms: settling down before 30, starting a family and getting an education and a job.

Using focus group interviews, Juberg discloses a finely nuanced repertoire of positioning strategies among the adolescents. This makes it untenable to speak of neat categorisations. The findings remind social workers that being a bit deviant in adolescence involves manoeuvres in social spaces that are fairly flexible. Sometimes, there are opportunities to be a "bad boy" or a "bad girl". At other times, there is plenty of legroom for the adoption of conventional norms.

In the third article of this issue, Kati Hämäläinen, Henna Pirskanen and Susanna Rautio address matters of data collection in sensitive areas. The national setting is Finland and the focus is on sensitive and contradictory family situations. The authors, all of whom use qualitative interviews, ponder the thin line between research and therapy. Can qualitative interviews, they wonder, serve both purposes? This is an important question given that in the tradition of Weber, social science has tended to keep objectivity and emotions apart in the research process.

Each of the three authors is involved in the study of sensitive and contradictory family circumstances in three distinct research projects:

- investigating how children in foster care define family and how they construe family relations;

- studying men's perceptions of their fathers' alcohol-related problems;

- exploring families' experiences of early service support. 
These are important areas of study in themselves. However, the authors are mainly concerned with sensitivity issues that they encounter during the research process itself. The centre of attention here is how the researchers handle their emotions when they are studying touchy issues.

In the fourth and final article, Gurid Aga Askeland and Anne Margrethe Sønneland highlight the challenges facing the repatriation of Chilean refugees who initially settled in Norway after the notorious coup d'état in Chile in 1973. As a result, both Chile and Norway are the national settings. In this fascinating study, the authors interviewed 13 Chilean returnees.

The data disclose a diaspora (from the Greek, ठıабторá: "scattering, dispersion") of different elements; among them are Chilean sociability and Nordic materialism. As one of the interviewees puts it, "When I think about Chile, I think about people. When I think about Norway, I think about the landscape".

Even though a romantic notion of a bygone, almost mythical Chile surfaces in some of the interviews, there is also the recognition that the Chile of today is no longer the land of Salvador Allende, but rather of neo-liberalism. That said, for some of the returnees going back to Chile represents a political act. It offers the chance to still keep working on the perpetual project called social justice. 